\title{
Antecedents of Enterprise Resource Planning and its Impact on Firm Perfromance with Supply Chain Integration as Mediating factor
}

\author{
MUHAMMAD MOINUDDIN QAZI ABRO*, ZAHID A. MEMON*, ASIF ALI SHAH*, AND \\ IFFAT BATOOL NAQVI* \\ RECEIVED ON 13.10.2016 ACCEPTED ON 22.11.2016 \\ ABSTRACT
}

\begin{abstract}
In today's knowledge based globalized business world, the contemporary organizations are thriving to apply the innovative as well as modern business techniques and tools in their products and processes regularly. Besides, the organizations give sufficient significance while building up their business organisms and operations in order to utilize the innovative methodologies alongside their other primary procedures. Based on the ERP (Enterprise Resource Planning) and prior literature on management of supply chain, this paper analyzed an integrated model of ERP assimilation and integration by using Saudi Arabian firms as a case. This paper addresses the questions (1) there is a positive link between technological, organizational and environmental factors and ERP implementation, and (2) that ERP implementation encourages SCI (Supply Chain Integration) and performance. The paper empirically examines the antecedents of ERP implementation on SCI which will lead towards the firm performance by using SEM (Structural Equation Modeling) as an approach. Moreover, ERP is used as a mediating factor by using quantitative data, collected from Tadawul. Tadawul is Saudi Arabian stock exchange, in which 167 firms are registered. The results of the paper, may add to the hypothetical comprehension of accomplishing a change in supply chain management, and might leave some imperative implications for the firms motivated by enhancing their supply chain performance. It is also found that the linkage from ERP implementation to $\mathrm{SCI}$ is very significant.
\end{abstract}

Key Words: Enterprise Resource Planning, Supply Chain Integration, Firm Performance, Saudi Arabia

\section{INTRODUCTION}

T

The most appreciated and dreaded manufacturers nowadays are tightly integrating and positively coordinating their supply chains. The relevant literature has revealed that the effective management of manufacturing processes is a potential source of competitive advantage and contemporary organizations are managing their manufacturing processes efficiently and effectively. Cagliano, et. al. [1] analyzed that due to in expanded level of products complexity and outsourcing techniques the competitions from one solitary organization is increased to the chains of organizations. Rice and Hoppe [2] stressed that the effective supply chain management leads to competitive advantage. In general, the organization strategy for manufacturing is concentrated

* Mehran University Institute of Science, Technology \& Development, Mehran University of Engineering \& Technology, Jamshoro.

Mehran University Research Journal of Engineering \& Technology, Volume 36, No. 2, April, 2017 [p-ISSN: 0254-7821, e-ISSN: 2413-7219] 
on the internal processes of manufacturing; however; in particular manufacturing strategy is concerned with the different nodes of supply chain, physical transformation of material as well as products assembly. Therefore, supply chain management is one of the important issues for many organizations. The contemporary organizations are gaining their competitive advantage not only through the integration of different business processes or business functions internally or managing their knowledge, but also through the external integration and alignment of business processes like their relationship with suppliers as well as customers. There are large numbers of studies which are contributing to the operations and manufacturing management literature. These contributions now-a-days are concentrated on how organizations can integrate their internal as well as external activities with their suppliers as well as customers. Moreover, the organizations are in the process as well as working hard to improve their internal processes and manufacturing operations by using different types of manufacturing practices. The advanced manufacturing practices techniques and their relationship with organizational performance is studied already, however, the relationship between manufacturing improvement programs like EPR and SCI is been rather neglected so far. Identifying the antecedents of the ERP system implementation and their relation to the supply chain integration should provide a better indulgent of the shared implications of ERP system implementation and $\mathrm{SC}$ integration. The research intends to explore the success factors of implementing ERP system, by addressing the research questions: what are the antecedents of implementing successful ERP system? And how will successful implementation of ERP system impact supply chain integration and the performance of the firm? This research contributes to the literature by being first to consider these issues from one particular country. Towards that end, the paper extends our knowledge about Internetenabled supply chains and identifies the greatest obstacles to their integration. This paper is structured in a way that this introductory section is followed by literature review of supply chain integration and enterprise resource planning. Then the next section summarizes the theoretical background of technology-organization- environment and resource based theory. Then the next section, presents the research model and the development of the hypotheses. The next section, discusses the planned methodology to test the research hypotheses, however, conclusions and future research avenues will be discussed in the last section.

\section{LITERATURE REVIEW}

\subsection{Supply Chain Integration}

SCM (Supply Chain Management) is an "integration of business processes" as defined by Kivimaa and Kern [3]. The conventional understanding in the SCM literature is that "the more integration the better supply chain performance". SCM also creates value for the organization, its partners as well as its shareholders (Lambert et. al. [4]). SCM and integration has been distinguished as major factor to oversee supply chains and accomplish leading performance (Carmeli and Tishler [5]). Bagchi and SkjoettLarsen [6] suggested that vertical integration in a supply chain must be exchanged with virtual integration and each node must focus on the processes which it implements better, leaving the rest of the chain to the other elements. The ultimate goal of this exercise is that the entire processes across the supply chain is designed, managed and coordinated like one single unit. However, there are numbers of researchers argued that close collaboration and integration are not the best solutions in every case (Hayes and Wheelwright [7]). Moreover, it is obligatory to reconsider the prevailing perspective of integrated supply chain management. Lee [8] has revealed that an integrated supply chain works more than the cost reduction for any manufacturing organization 
There are a limited number of studies which mapped the real level of integration among the different nodes of the supply chain. The key components of a supply chain are relationship of the origination with its suppliers, interaction between the nodes of the chain, business processes and horizontal as well as vertical information flow. Traditional supply chain management system is different from the contemporary modern and integrated supply chain. The traditional supply chain has many disadvantages, for example at every level in reverse in the supply chain, the precision of the estimate will decrease due to the expansion in the vulnerability of interest as an aftereffect of the disengaged data streams. Mistaken estimate more often than not makes surplus stock for both suppliers and producers. Another disadvantage is that the traditional chain typically responds very slowly to the demand and estimate changes and as a result, the traditional supply chain normally aspects environmental problems; therefore, the academic literature on supply chain has been encouraging the need for supply chain improvement to deal with the environmental vagueness or uncertainty, as discussed by Lee [8]. Graham and Stevens [9] stated that the supply chain literature has concluded that the integration of supply chain is based on internal as well as external integration.

\subsection{Enterprise Resource Planning}

The consolidated strategic manufacturing model, which was established during the different stages of ERP as well as SCM has identified a number of treadles, characterized as structural and infrastructural model. This is being used by the organizations to develop their manufacturing strategies in terms of quality, cost, flexibility and delivery (Skinner [10]; Hill [11]; Hayes and Wheelwright [12]). Besides the common efforts to keep the organization up to date in improving their operations, two other major areas of investment should be taken into considerations. The first area is the investment in integrated information systems, specifically ERP, while its application and manufacturing processes is subtle (Qing, et. al. [13]). Davenport [14] suggested that the implementation of the ERP system by different organizations is being broadly studied in current literature, concentrating especially on the challenges during the implementation process. ERP implementation is related with a greater degree of information flowing with suppliers. ERP system is premeditated in order to increase the information inside the organization. The second area is the investment in particular practices that refer to lean production and TQM (Total Quality Management) models. These practices aim to gain a focus in process of the manufacturing arrangement and a pull manufacturing system, and to improve productivity and quality through these quality management techniques. There is vast variety of literature available on these manufacturing practices; however, this paper focuses on the first area which is the investment in integrated information systems, specifically ERP systems. The integration of supply chain is examined in the academics from many perceptions. For instance, Narasimhan and Das [15] distinguished between SCI, customer integration, distribution integration, information integration as well as logistics integration. However, this paper concentrates on the upstream side of supply chain and its integration mechanism, and in particular those nodes of the chain which are intended to integrate the production processes. Having said all this, this paper evaluates the integration techniques espoused by the different organizations. These integration techniques are named as JIT (Just in Time), Lean manufacturing, etc. However, it is argued that, within these practices, it is necessary to recognize the distinctive factors. Cagliano, et. al. [16] revealed that several practices are intended to integrate the forward physical flows. These both methods of assimilating supply chain methods are not related in nature. The first way requires a closer combination of the manufacturing systems between customers as well as

Mehran University Research Journal of Engineering \& Technology, Volume 36, No. 2, April, 2017 [p-ISSN: 0254-7821, e-ISSN: 2413-7219] 
suppliers. The second way of integration or assimilation is intended to leverage information from supply chain participants to improve internal processes and operations management systems. The integration practices have been widely discussed in the academic literature as well as supported empirically. However, many studies support that if there is a greater level of integration there will be greater performance of the organization (Cagliano, et. al. [16]). Therefore, this paper is not planned to analyze the importance of SCI methods or mechanisms but however to evaluate their relation or association with ERP system.

\section{THEORETICAL BACKGROUNDS}

This section provides TOE (Technology Organization Environment) framework and RBV (Resource Based View) as the theoretical rationale of the suggested model. The role of a firm as an initial adopter of ERP is still crucial for value creation to the firm. Therefore, this paper identifies the determinants of ERP implementation, its use and value creation process on the performance of firm.

\subsection{TOE Framework}

In 1990, Tornatzky and Fleischer [17] developed a framework based on TOE, in which three contexts of firm which might affect the ERP or any other IT (Information Technology) based process are introduced. These contexts are based on technological issues, organizational issues as well as environmental issues. Technological issues or context is defined as the extant any innovative technology is relevant for the firm. Organizational context is defined as descriptive measures which might influence in technology adoption as well as implementation such as size and scope, and the resources. However, environment context is in which a firm operates [17]. TOE is helpful in order to explain the implementation of innovative technologies, because its driving force is well articulated in a comprehensive manner. Bradford and Florin [18] argued that the technological, organizational and inter- organizational characteristics are considered as strategic drivers for technology diffusion. Based on TOE framework, Brazel and his colleague [19] investigated three factors which might effect on EDI (Electronic Data Interchange) adoption in small and medium sized firms, which are organizational readiness, the external pressure organization is facing or might face, and the benefits the organization can or will receive. However, for the purpose of this paper, the antecedents of ERP use in the context of innovative technology adoption are identified.

\subsection{Resource-Based Theory}

RBV theorizes that a firm produces value by combining its assorted and steady resources that are VRIN (Valuable, sporadic, Inimitable or Non-Substitutable) against competitors. Resources are more likely to support firms' sustained competitive advantages when they are protected by "separating tools" such as time-compression diseconomies, historical exclusivity and fundamental vagueness. In the literature, the RBV is used to evaluate the IT capabilities of the firms and its commercial value. Begek et. al. [20] argues that business value of IT appeals the amount through which IT is used by the firms towards their value chain. It is further argued that these IT capabilities initiated by ERP adoption and implementation enable firms to gain a competitive advantage against their competitors. Fig. 1 depicts theoretical framework.

\section{HYPOTHESES DEVELOPMENT}

\subsection{Technological Context}

Technological context is considered as which the firms can accomplish their competitiveness through innovation. The perceived innovative advantage as the level of the relative point of interest that ERP conveys to the firm the authors assembled this advantage into immediate and aberrant advantages. Direct advantages allude to operational cost investment funds identified with the inward effectiveness which incorporate enhancing

Mehran University Research Journal of Engineering \& Technology, Volume 36, No. 2, April, 2017 [p-ISSN: 0254-7821, e-ISSN: 2413-7219] 
information exactness, diminished stock levels and decreased exchange costs. Aberrant advantages allude to the effect of ERP on the business procedure and associations with different firms. In this paper, the direct and indirect benefits out of ERP adoption and use for the technological context are considered. The above arguments lead to the following hypothesis.

\section{H1(a): Technology factor is positively associated with ERP implementation.}

\subsection{Organizational Context}

The previous papers supported the notion that the more organizational resources firms have, the greater value they can get from IT use (Carneli and Tishler [21]; Clayton [22]). It is obvious that, sufficient organizational resources cause a successful IT implementation. Financial resources are defined as capital asset to afford the cost of ERP installation, implementation, maintenance, and many other subsequent matters. Technology resources take into account the level of technological knowledge and expertise within organization. These resources can measure organizational readiness. Thus, the more organizational resources are available, the more likely firms can adopt and implement ERP. The above argument leads to the following hypothesis.

\section{H1(b): Organizational Factor is positively associated} with ERP implementation.

\subsection{Environmental Context}

Bagchi and Skjoett-Larsen [23] expressed that diverse external factors that might influence the firms in order to use any innovative as well as latest technology are mentioned everywhere in the previous literature. For the purpose of this paper, two environmental factors are identified which might affect ERP implementation as well as adoption are pressure from external forces and the supply chain partner issues. External pressures are the pressures the firm getting from external environment in order to adopt ERP system (Ibrahim, et. al. [24]). Xu and his colleagues [25] have suggested that the pressure from external environment is a major factor which might leads to diffuse the innovation. Firms often adopt new innovative technology owing to pressure from industry, market competition and government regulations. The other factor is partner readiness. Many studies mentioned that trading partners' readiness in environment context is very important enabler to technology adoption (Zabjek et. al., [26]). It refers to combination of partner's technology familiarity and willingness. Technology familiarity is defined by Murphy and Simon [27] as the degree to which

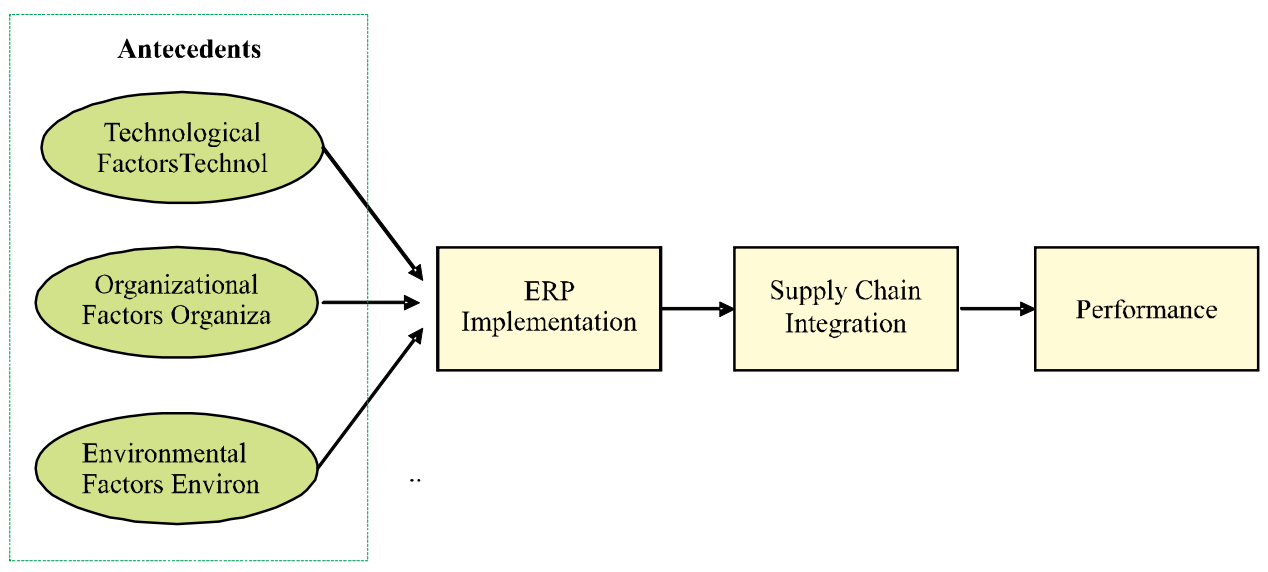

FIG. 1. THEORETICAL FRAMEWORK 
employees feel comfortable to manage to technology including internet and other software is diffused in the population. The more partners are willing to adopt and implement ERP, the greater ERP use will be. The above argument leads to the following hypothesis.

\section{H1(c): Environmental factor is positively associated with ERP implementation.}

\subsection{ERP Implementation}

Since mid-1990s, numerous organizations have moved their IT innovations methodology from creating in-house frameworks in order to obtain application programming, for example, endeavor asset arranging (ERP) frameworks. However, despite the strategic importance, the implementation of ERP raised the issue for both researchers and decision makers in business industries.

\subsubsection{Measure of the Success in ERP Systems Implementation}

As for the definition of a successful ERP implementation success, there are several different sets of instruments developed by the researchers. By the literature review, one of the schemes was well accepted, which was given by Zhe, et. al. [28]. By selecting and modifying the instrument developed by [28], and involved into measurements for the success of ERP implementation. The measurements are defined in this paper by the following six measurements: (1) User satisfaction, including the satisfaction of inside users (employee and managers), and outsider users (suppliers' and customers); (2) Intended business performance improvements, which makes sure the performance is improved towards the right direction for this firm; (3) On time; (4) budget limits; (5) Acceptance of system, which considers the IT fertility supports, and (6) Culture acceptance, which emphasizes the matching of the ERP system with firm culture.

\subsection{Supply Chain Integration}

SCI can be effectively managed by integrating business processes internally and externally across different nodes of supply chain. SCI can be defined as the process of collaboration and interaction through which organizations can operate in order to achieve their objectives. There are numerous studies which have confirmed the integration of supply chain benefits for all the stock holders including customers as identified by Wang and Boon-itt [29].

\subsection{The Relationship between ERP Implementation and SCM Integration}

The implementation problems fall into the following folders: un-matching business process, lack of top management supports, insufficient education and training, as well as the culture modification mentioned above. . EPR was believed to be a strong support to SCM integration and performance from the following two perspectives.

The first perspective is the development of mass customization. Mass customization is defined as a manufacturing philosophy that modifying as well as fitting a product which can fulfill the specific needs of customer. The characteristics of mass customization requires the fast, widely, and actually data exchange, which is one of the strengths in ERP system. As long as customers can design their products, ERP system could schedule and manage the production or services under the mass customization philosophy. The second perspective is the process of standardization in supply chain. The essential issues in SCM integration is how to standardize the performance and operations of the firms within supply chain. Due to the professional and best-practice designing in the ERP implementations, these standards provide a solid platform for better

Mehran University Research Journal of Engineering \& Technology, Volume 36, No. 2, April, 2017 [p-ISSN: 0254-7821, e-ISSN: 2413-7219] 
performance of SCM integration. The above wide analysis on the relationship between the ERP and SCI leads to the following hypotheses.

\section{H2: ERP is positively associated with supply chain integration.}

\subsection{Performance Measures}

Performance is utilized as the measure for effective supply chain. The research model which was proposed by Kaplan and Norton [30] emphasized on the enclosure of internal business functions processes, financial issues, customer, learning and growth views as reasonable measures of organizational performance. These factors were selected on the basis of, financial measures for example return on investment, growth in sales and share in the market, the second factors or measure was performance and operational for example Product life cycle, time to enter in the markets for new products and supplier issues [30]. Both these financial as well as operational factors and measures are therefore, taken up into consideration in this paper. Having said all this, it is therefore, hypothesized that the higher the level of integrated coordination the greater will be the benefits. This will lead to the following hypothesis as depicted in Fig. 2.

\section{H3: Supply chain integration is positively associated with firm's performance.}

\section{METHODOLOGY}

The quantitative research methodology was adopted for this research; the survey questionnaire was developed by using three stages. At the first stage, the relevant measures of technological, organizational and environmental factors, ERP implementation, supply chain integration and its impact on performance in the literature was carried out to develop the survey questionnaire. At the second stage, a few meetings with managers to gauge the content and validity of the questionnaire were conducted. At the third stage, the questionnaire was pretested as a piloting with 10 originations to further check the validity and overall readability of the questionnaire. Obviously, these 10 organizations were excluded then from the main survey. Data was collected from a stratified random sample of organizations from the Saudi Arabia. By sampling an entire kingdom, the survey questionnaire was sent to the Saudi Stock Exchange (TADAWUL) listed organizations, which are 172 in number to date. Typical respondents were operations or general managers and therefore the data was collected from managers having enough seniority level to know about their organization. Of the 82 questionnaires returned as total, 12 were incomplete, either blindly filled by the respondents or incomplete. The remaining 70 were useable, complete and valid questionnaires. These 70 questionnaires were used then for the analysis; it represents a response rate $40 \%$. Convenience sampling technique was used because all the usable questionnaire were used for the analysis

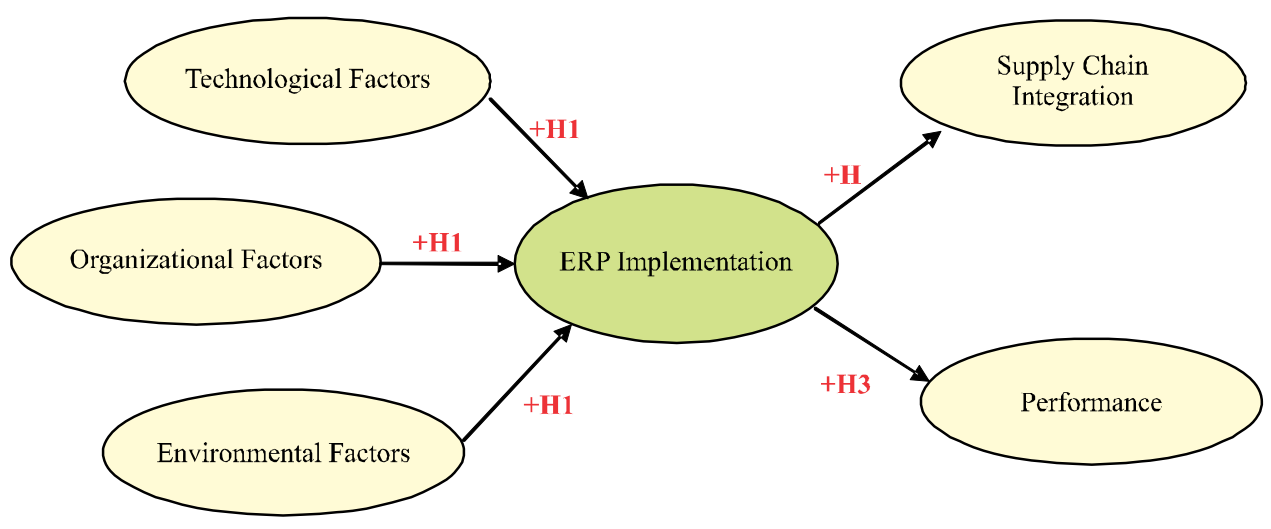

FIG. 2. SEM CONCEPTUAL MODEL 


\subsection{Mediating Supply Chain Integration Constructs Measurement}

The research practice in management research is dominantly based on SEM. For this paper, we have developed theoretical foundations and have used moderating factor. SEM technique is used to validate the research model. It is evident that, SEM examines the spontaneous and efficient effect of three independent variables (Technological, Organizational and Environmental) on ERP implementation and then the impact of these independent variables on the SCI and performance. The theoretical framework (Fig. 1) is operationalized by using the SEM shown in Fig. 2. Following the rudimentary analyses of the data descriptively, which includes examination for outliers, data normality, kurtosis, skewness, mode, mean, median and standard deviations. The variables are grouped into a priori conceptualizations of appropriate sub-scales for barriers, SCI, and performance. The data is normally distributed and there are no outliers identified in the data. In the questionnaire survey, SCI as well as ERP implementation are measured based upon various initiatives that organizations usually use to coordinate supply chains using the ERP. In this context, the available literature as well as in depth interviews with the managers during the quantitative survey development helped to ground these measures. The extent of implemented SCI for each organization was measured on 1-5 Likert-scale $(1=$ not at all to $5=$ fully implemented).

\subsection{Independent and Dependent Construct Measurement}

The technological factors, organizational factors and environmental factors to ERP implementation to the SCI are likewise grounded in the literature. Factors are measured on 1-5 Likert scales ( 1 =insignificant; 5 = highly significant) in terms of their ERP implementation and SCI. Multiple iterations of CFA (Confirmatory Factor Analysis), are again used for scale purification and to help ensure reliable measures of technological, organizational and environmental factors. Four variables are excluded to form the resulting three-item scales for barriers shown in Fig. 2. Two of the excluded items or variables were constraints and awareness of innovative technology. It is noticed that, these two items or barriers are overlapping with technology costs/benefit items. The measures for performance are also reported in the literature. The degree of firm performance was based on the actual percentage of procurement and sales revenue/turnover conducted by using the SCI. It is, therefore, believed that the performance of firm is definitely based on faster delivery time, reduction in transaction costs as well as inventory management or turnover related to SCI (1-5 Likert: $1=$ none; $5=$ extensive).

\subsection{Validity and Reliability of Data}

The reliability of the factors seems satisfactory with Cronbach alphas of $70 \%$ as shown in Table 1 . Construct validity of the factors is measured by testing that whether these factors are loaded in a scale on a common factor analysis. This is achieved by looking at the Eigen values of the factors, which shows all eigen values are exceeding the minimum required threshold of 1.0 .

\section{RESULTS AND DISCUSSION}

This paper used SEM in order to test the hypotheses which are developed earlier. Table 2, tabulates the goodness of model fit for Fig. 2's SEM.

The modification figures have revealed that some of the variables must be undisturbed. For instance, decreased exchange costs contrarily related with yearly percent of offers/turnover by utilizing production network then again innovation expenses and advantages are not exhibited conversely with specialized aptitudes. In these cases, a blunder covariance between the two elements must be incorporated and the estimation model may be adjusted as need be. As before, modification figures are cautiously used and a parameter link is only released if it be interpreted substantively regarding both the directions. Table 3, tabulates the direct and indirect effects between the independent, mediating, and dependent variables for the model and Fig. 3 depicts the direct effects of conceptual

Mehran University Research Journal of Engineering \& Technology, Volume 36, No. 2, April, 2017 [p-ISSN: 0254-7821, e-ISSN: 2413-7219] 
model. Overall, there is strong relation and support for the hypothesized variables supply chain and firm performance. As predicted, SCI (H2) has strong direct effects on the ERP implementation and then firm (H3). Furthermore, technological factors (H1a), organizational factors (H1b), and environmental factors (H1c) all have significant positive effects on the degree of SCI which leads towards firm performance. These findings might suggest that the organizational factors are the single most important factors when it comes to integrating the supply chain. In other words, Organizational factors most accelerating the SCI process.

TABLE 1. MEASUREMENT ANALYSIS: FACTORS (TECHNOLOGICAL, ORGANIZATIONAL AND ENVIRONMENTAL), ERP IMPLEMENTATION, SUPPLY CHAIN INTEGRATION AND FIRM PERFORMANCE.

\begin{tabular}{|c|c|c|c|c|}
\hline \multirow{2}{*}{ Measures } & \multirow{2}{*}{ Cronbach' Alpha } & Average Interscale \\
Co-Relate & & \multicolumn{2}{|c|}{ Average Item Total Correlations } \\
\cline { 3 - 5 } & & 0.83 & Non-Scale Items & Scale Items \\
\hline Technological Factors & 0.69 & 0.28 & 0.20 & 0.76 \\
\hline Organizational Factors & 0.80 & 0.21 & 0.23 & 0.60 \\
\hline Environmental Factors & 0.78 & 0.18 & 0.20 & 0.19 \\
\hline ERP Implementation & 0.82 & 0.17 & 0.18 & 0.59 \\
\hline Supply chain integration & 0.72 & 0.19 & 0.19 & 0.64 \\
\hline Performance & & & & 0.75 \\
\hline
\end{tabular}

TABLE 2. STATISTICS OF STRUCTURAL EQUATION MODEL FIT.

\begin{tabular}{|c|c|}
\hline Statistics for Model Fit & $\mathrm{df}=83$ \\
\hline $\mathrm{X} 2$ & $72.44(\mathrm{p}<0.81)$ \\
\hline $\mathrm{X} 2 / \mathrm{df}$ & $0.86(? 22.00) \mathrm{a}$ \\
\hline GFI & $0.99(>0.90) \mathrm{a}$ \\
\hline AGFI & $0.97(>0.90) \mathrm{a}$ \\
\hline RMSR & $0.04(<0.10) \mathrm{a}$ \\
\hline NNFI & $1.00(\sim 1.00) \mathrm{a}$ \\
\hline NFI & $0.98(>0.90) \mathrm{a}$ \\
\hline Hotelling's Critical N & $785(>200) \mathrm{a}$ \\
\hline
\end{tabular}

TABLE 3. DIRECT AND INDIRECT EFFECTS OF SEM

\begin{tabular}{|c|c|c|c|}
\hline & $\begin{array}{l}\text { Hypothesis H1(a) } \\
\text { Technology Factor }\end{array}$ & $\begin{array}{l}\text { Hypothesis H1(b) } \\
\text { Organizational Factor }\end{array}$ & $\begin{array}{l}\text { Hypothesis H1(c) } \\
\text { Environmental Factor }\end{array}$ \\
\hline $\begin{array}{c}\text { Direct Effects } \\
\text { ERP implementation }\end{array}$ & 0.19 & 0.37 & 0.17 \\
\hline Indirect Effects & \multirow{2}{*}{0.15} & \multirow{2}{*}{0.30} & \multirow{2}{*}{0.14} \\
\hline SC Integration & & & \\
\hline Performance & 0.15 & 0.31 & 0.14 \\
\hline Direct Effects & \multicolumn{3}{|c|}{ Hypothesis $\mathrm{H} 2$ and $\mathrm{H} 3$} \\
\hline SC Integration & 0.82 & & \\
\hline Firm Performance & 0.80 & & \\
\hline
\end{tabular}

Mehran University Research Journal of Engineering \& Technology, Volume 36, No. 2, April, 2017 [p-ISSN: 0254-7821, e-ISSN: 2413-7219] 


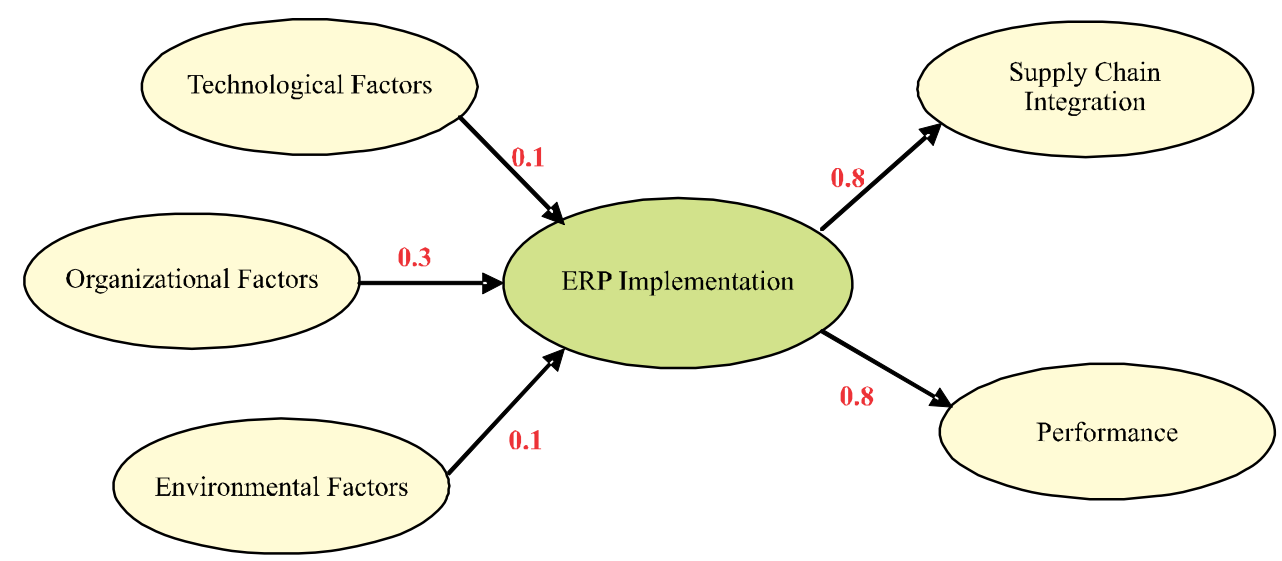

FIG. 3. RESULTS OF SEM MODEL

\section{CONCLUSION}

In this paper, the relationship between SCI and ERP implementation as well as the antecedents of ERP implementation are investigated by using sample of Saudi firms. This paper provides theoretical rationale for ERP implementation and its impact on SCI. Three antecedents of ERP based on TOE framework are identified. The determinants are considered in technological, organizational and environmental context. This is the first ever study to investigate the drivers which encourage the organizations to adopt and implement ERP from Saudi Arabia context. The results support the literature that ERP plays an important role in improving the firm performance. There is consistent evidence that technological, organizational and environmental factors are playing an important role to ERP implementation as well as SCI, which leads to firm performance, in particular, the key to implementing ERP overcoming the organizational factors. The SCI must be coordinated tightly, and manufacturers should not ignore or neglect their internal obstructions in order to successfully implement the ERP system in their organizations. The results of this paper, suggest that the managers who are interested in improving their supply chain by using ERP must focus on organizational factors first. The subsequent literature in this area has revealed that there are three steps to successful ERP implementation: (1) Unfreezing stage (2) Trial and Error stage, and (3) Refreezing stage. The results obtained from this paper suggest that the organizations which have implemented ERP system effectively are able to successfully integrate their supply chain process as well. This paper provides some of the basic building blocks for addressing the antecedents towards the ERP implementation and its role towards supply chain integration in Saudi firms. The next research might be considered the supply chain and its eintegration by collecting a data at large scale. The findings show a need for a thorough need of policy solutions for encourage the supply chain integration for the Saudi firms. It is additionally perceived that developing solutions for any resource planning system or framework needs a social change rather than technological change. There are two policy implications of this study; firstly, there is a need for basic information provision to overcome lack of knowledge about any resource planning system and secondly, the information and knowledge available about the change, and even the motivation to act, are important for Saudi firms. There is a need for supportive institutions and infrastructure (e.g., affordable and efficient support) to enable action at the firm level.

Mehran University Research Journal of Engineering \& Technology, Volume 36, No. 2, April, 2017 [p-ISSN: 0254-7821, e-ISSN: 2413-7219] 


\section{ACKNOWLEDGEMENTS}

Authors wish to express a sincere thanks to all those who graciously agreed to participate in this study. Furthermore, authors would like to thank Mehran University of Engineering \& Technology, Jamshoro, Pakistan, for facilitating this research and anonymous reviewers are also acknowledged for their diligent review and constructive comments.

\section{REFERENCES}

[1] Cagliano, R., Caniato, F., and Spina, G., "The Linkage between Supply Chain Integration and Manufacturing Improvement Programs", International Journal of Operations \& Production Management, Volume 26 No. 3, pp. 282-299, 2006.

[2] Rice, J.B., and Hoppe, R.M., "Supply Chain Versus Supply Chain: The Hype and the Reality", Supply Chain Management Review, September-October, 2001.

Kivimaa, P., and Kern, F., "Creative Destruction or Mere Niche Creation? Innovation Policy Mixes for Sustainability Transitions", SPRU Working Paper Series, Sussex University, Brighton, 2015.

[4] Lambert, D.M., Cooper, M.C., and Pagh, J.D., "Supply Chain Management: Implementation Issues and Research Opportunities", The International Journal of Logistics Management, Volume 9, No. 2, pp. 1-19, 1998.

Carmeli, A., and Tishler, A., The Relationship between Intangible Organizational Elements and Organizational Performance", Strategic Management Journal, Volume 25, pp. 1257-1278, 2004.

[6] Bagchi, P., and Skjoett-Larsen, T., "Supply Chain Integration: A European Survey", International Journal of Logistics Management, Volume 16 No. 2, pp. $275-294,2005$.

Hayes, R.H., and Wheelwright, S.C., "Restoring Our Competitive Edge”, Collier Macmillan, New York, NY, 1984

Lee, H.L., "Creating Value through Supply Chain Integration", Supply Chain Management Review, Volume 4, No. 4, pp. 30-6, 2000.
Graham, C., and Stevens, M.J., "Integrating the Supply Chain-25 Years" International Journal of Physical Distribution \& Logistics Management, Volume 46, No. 1, pp. 19-42, 2016.

[10] Skinner, W., "Manufacturing - Missing Link in Corporate Strategy", Harvard Business Review, Volume 47 No. 3, pp. 136-44, 1969.

[11] Hill, T.J., "Manufacturing Strategy", The Strategic Management of Manufacturing Function, Macmillan, London, 1993.

[12] Hayes, R.H., and Wheelwright, S.C., "Restoring our Competitive Edge", Collier Macmillan, New York, NY, 1984.

[13] Qing, C., Donald, R.J., and Hong, S., "Contained Nomadic Information Environments: Technology, Organization, and Environment Influences on Adoption of Hospital RFID Patient Tracking", Information \& Management, Volume 51, pp. 225-239, 2014

[14] Davenport, T.H., "Putting the Enterprise Into the Enterprise System", Harvard Business Review, Volume 16 No. 2, pp. 121-31, 1998.

[15] Narasimhan, R., and Das, A., "The Impact of Purchasing Integration and Practices on Manufacturing Performances", Journal of Operations Management, Volume 19, pp. 593-609, 2001

[16] Cagliano, R., Caniato, F., and Spina, G., "The Linkage between Supply Chain Integration and Manufacturing Improvement Programs", International Journal of Operations \& Production Management, Volume 26 No. 3, pp. 282-299, 2006.

[17] Tornatzky, L.G., and Fleischer, M., "The Processes of Technological Innovation”, Lexington, MA: Lexington Books, CL Fifth, T173.8 .T67, 1990.

[18] Bradford, M., and Florin, J., "Examining the Role of Innovation Diffusion Factors on the Implementation Success of Enterprise Resource Planning Systems", International Journal of Account Information System, Volume 4, No. 3, pp. 205-211, 2003.

[19] Brazel, J., and Dang, L., "The Effect of ERP System Implementations on the Management of Earnings and Earnings Release Dates", Journal of Information System, Volume 1, No. 2, pp. 22-32, 2008. 
Bergek, A., Jacobsson, S., Carlsson, B., Lindmark, S., and Rickne, A., "Analyzing the Functional Dynamics of Technological Innovation Systems: A Scheme of Analysis", Research Policy, Volume 37, pp. 407-429, 2008.

[21] Carmeli, A., and Tishler, A., "The Relationship between Intangible Organizational Elements and Organizational Performance", Strategic Management Journal, Volume 25, pp. 1257-1278, 2004.
[25]

Xu, W., Peiyu, O., and Weiguo, F., "Antecedents of ERP Assimilation and its Impact on ERP Value: A TOE-Based Model and Empirical Test", Information Systems Frontiers, Volume 16, No. 1, pp, 1-18, 2015.

[26] Zabjek, D., Kovacic, A., and Stemberger, M. I., "The Influence of Business Process Management and Some Other CSFs on Successful ERP Implementation", Business Process Management Journal, Volume 15, No. 4, pp. 588-608, 2009.

[27] Murphy, K.E., and Simon, S.J., "Intangible Benefits Valuation in ERP Projects", Information Systems Journal, Volume 12, No. 4, pp. 301-320, 2000.

[28] Zhe Z., Matthew K.O., Lee, P.H., Liang, Z., and Xiaoyuan, H., "A Framework of ERP Systems Implementation Success in China: An Empirical Study", International Journal of Production Economics, No. 98, pp. 56-80, 2005.

[29] Wang, C., and Boon-itt, S., "The Influence of Institutional Norms and Environmental Uncertainty on Supply Chain Integration in the Thai Automotive Industry", International Journal of Production Economics, No. 115, pp. 400- 410, 2008.

[30] Kaplan, R.S., and Norton, D.P., "The Balanced Scorecard", Harvard Business School Press, Boston, MA, 1996. 